\title{
Peek Acuity vs Snellen Chart for visual impairment screening in leprosy: a cross-sectional study
}

\author{
Yunia Irawati ${ }^{\mathrm{a}, \mathrm{b}}$, Anna Puspitasari Bani ${ }^{\mathrm{c}}$, Krystle Gabriella $^{\mathrm{d}}$, \\ Anis Fitriana ${ }^{d}$, Carennia Paramita ${ }^{\mathrm{d}}$, Made Susiyanti ${ }^{\mathrm{b}, \mathrm{e}}$, \\ Tri Rahayu ${ }^{\mathrm{b}, \mathrm{f}}$, Gitalisa Andayani ${ }^{\mathrm{b}, \mathrm{g}}$ \& Yeni Dwi Lestari ${ }^{\mathrm{h}}$ \\ ${ }^{a}$ Division of Plastic and Reconstructive Surgery, Department of \\ Ophthalmology, Faculty of Medicine, Universitas Indonesia, Dr. Cipto \\ Mangunkusumo Hospital, Jakarta, Indonesia \\ ${ }^{\mathrm{b}}$ JEC Eye Hospitals and Clinics, Jakarta, Indonesia \\ ${ }^{\mathrm{c}}$ Division of Strabismus, Department of Ophthalmology, Faculty of \\ Medicine, Universitas Indonesia, Dr. Cipto Mangunkusumo Hospital, \\ Jakarta, Indonesia \\ ${ }^{\mathrm{d}}$ Research Assistant, Department of Ophthalmology, Dr. Cipto \\ Mangunkusumo Hospital, Jakarta, Indonesia \\ ${ }^{\mathrm{e}}$ Division of Infection and Immunology Medicine, Department of \\ Ophthalmology, Faculty of Medicine, Universitas Indonesia, Dr. Cipto \\ Mangunkusumo Hospital, Jakarta, Indonesia \\ ${ }^{\mathrm{f}}$ Division of Refraction, Department of Ophthalmology, Faculty of Medicine, \\ Universitas Indonesia, Dr. Cipto Mangunkusumo Hospital, Jakarta, \\ Indonesia \\ ${ }^{\mathrm{g}}$ Division of Vitreoretina, Department of Ophthalmology, Faculty of \\ Medicine, Universitas Indonesia, Dr. Cipto Mangunkusumo Hospital, \\ Jakarta, Indonesia \\ ${ }^{\mathrm{h}}$ Division of Community Ophthalmology, Department of Ophthalmology, \\ Faculty of Medicine, Universitas Indonesia, Dr. Cipto Mangunkusumo \\ Hospital, Jakarta, Indonesia
}

Submitted 20 July 2020; Accepted 10 August 2020

\begin{abstract}
Summary
Objective: Leprosy is a chronic infectious disease caused by Mycobacterium leprae, which has a high incidence of ocular involvement. Due to the need for good vision for leprosy patients, visual acuity becomes an essential early screening examination. The Snellen Chart has been commonly employed as the standard for measuring visual acuity. Nevertheless, it is immobile and time-consuming. A smartphone-based application, Portable Eye Examination Kit (Peek Acuity), is already known to be
\end{abstract}

\footnotetext{
Correspondence to: Yunia Irawati, Division of Plastic and Reconstructive Surgery, Department of Ophthalmology, Faculty of Medicine, Universitas Indonesia, dr. Cipto Mangunkusumo Hospital, JEC Eye Hospitals and Clinics, Jakarta, Indonesia (e-mail: yunia_irawati@yahoo.com)
} 
accessible, reliable and easy to use for measuring visual acuity. This study examines the reliability of Peek Acuity in performing visual acuity screening for leprosy patients. Methods: A population-based cross-sectional study was carried out at a leprosy settlement village near Sitanala Hospital, Tangerang and Alverno Hospital, Singkawang. Participants' uncorrected visual acuity was measured using both the Snellen Chart and Peek Acuity. The scores were converted into logMAR.

Results: This study involved 347 subjects which included 692 eyes (2 eyes were anophthalmic). The mean difference between the Snellen chart and Peek Acuity was $0.11 \log$ MAR ( $95 \%$ CI, 0.096 to 0.13 ). Linear regression analysis showed no statistically significant difference between the Snellen Chart and Peek Acuity measurements $(P=0.98)$. Cohen's Kappa and concordance rate of visual acuity measured with Peek Acuity and Snellen Chart were 0.65 and 0.83 .

Conclusion: Peek Acuity is an accurate and repeatable visual acuity screening tool as effective as the Snellen Chart, which also can be used for leprosy patients to overcome barriers in accessing eye health services, especially in rural areas.

Keywords: Leprosy, visual acuity, visual impairment, Snellen chart, Peek Acuity, $\log$ MAR

\section{Introduction}

Leprosy is a chronic infectious disease caused by Mycobacterium leprae, with a high incidence of ocular involvement due to nerve damage or infiltration by the bacterium itself. Globally, it is estimated that $70-75 \%$ of leprosy patients have ocular complications, $10-50 \%$ of whom have severe ocular impairment, potentially leading to blindness. ${ }^{1}$ Severe visual impairment or blindness in leprosy is disastrous, as it may preclude self-care in patients who have already had sensory function loss of their limbs and developed visible deformities. Due to the needs of good vision for leprosy patients, visual acuity undoubtedly becomes an essential early screening examination..$^{2,3}$

Visual acuity can be measured using various methods, such as the Snellen Chart and Optotype. The Snellen Chart has been commonly employed as the standard for measuring visual acuity in daily practice due to its familiarity, well-recognized scoring system, small chart size and the speed of performing the test. Nevertheless, it is limited by the non-geometric progression in the letter sizing from line to line and the inconsistent number of letters per line. The examiner needs to ensure good natural light and place the chart at 6 meters or 20 feets distance. Moreover, lack of systematic approach to letter legibility and secondary effects such as crowding could lead to measurement bias. ${ }^{4-6}$ The Snellen Chart's limitations have been overcome by the development of the logarithm of the minimum angle resolution ( $\log$ MAR) chart, which has since become the standard method of measuring visual acuity for clinical research. ${ }^{7}$ However, $\log$ MAR has not been widely used in routine clinical practice because it is time-consuming and has an unfamiliar scoring system. ${ }^{4-6}$ Other visual acuity testing equipment such as Optotype is often expensive, ponderous and immobile which makes it difficult to implement in low-middle income countries, particularly in rural areas where there are fewer health professionals and inaccessible ophthalmic healthcare facilities. ${ }^{8}$

Indonesia is endemic for leprosy and is the country with the third highest number of new cases each year, after India and Brazil. Over 19, 000 new cases were reported in 2018. Facilities and health access in rural and suburban area are limited, so new methods that are more practical but still effective for visual acuity screening are required. 
Reducing the burden of visual impairment in leprosy patients is a major ophthalmic concern in Indonesia , and depends upon early screening and intervention. In this era of globalization, the number of smartphone users is forecast to grow and the technology has evolved rapidly in providing accessibility to health care. A logMAR style smartphone-based application called Portable Eye Examination Kit (Peek Acuity) is already known to be accessible, reliable and easy to use. ${ }^{5,7}$ Peek Acuity use only needs 2-3 meters in distance to measure visual acuity, much shorter than the Snellen Chart requires. Peek Acuity has the logMAR measurement option built into the application. The examination is quicker because the results will be automatically converted into logMAR. Optimizing the use of Peek Acuity can further reduce the cost of visual acuity screening. This study examines the reliability of Peek Acuity in performing visual acuity screening for leprosy patients to overcome barriers in accessing ophthalmic healthcare, by comparing results of visual acuity measured with Peek Acuity and the Snellen Chart.

\section{Methods}

STUDY DESIGN, SETTING AND POPULATION

A population-based cross-sectional study was carried out in April 2018 at a leprosy settlement village near Sitanala Hospital, Tangerang, Banten Province, and in July 2019 at Alverno Hospital, Singkawang, West Kalimantan Province. We conducted an examination on residents in the Sitanala leprosy village because of the large number of former leprosy patients in the area. We also conducted an examination in Singkawang because of the existence of Alverno Leprosy Hospital. The hospital does not have an ophthalmologist, so eye screening for leprosy patients is needed at the hospital.

Coordination with stakeholders in the field, including the local government, hospitals, patients and local people, was carried out. Before the program began, we announced the forthcoming eye examination to the local people and leprosy patients . During the activity, we recorded the patients' identity, employment status, income, education level, marital status, ethnic origin, and ophthalmology quality of life index using the National Eye Institute-Visual Function Questionnaire 25 (NEI-VFQ 25) .

Eyes were examined for visual acuity with the Snellen chart and Peek Acuity. The Peek Acuity app had been downloaded and installed prior to the program. We also performed the best corrected visual acuity examination, intra-ocular pressure examination using non-contact tonometry, corneal sensibility examination using esthesiometer, tear production examination using the Schirmer test, examination of the anterior eye chamber using a slit lamp, and posterior eye chamber by fundoscopy. Screening for eye diseases such as trichiasis, entropion, ectropion, lagophthalmos, dacryocystitis, conjunctivitis, pterygium, episcleritis, scleritis, keratitis, uveitis, cataract, and retinopathy were included . Besides eye examination, we checked skin health status and screened for disabilities of the extremities. A flow chart describing our examination procedures has been published previously. ${ }^{11}$

There were 265 patients at Sitanala Hospital, of whom 255 patients (508 eyes, 2 eyes were anophthalmic; 10 patients were excluded) were included and 99 patients at Alverno Hospital , of whom 92 patients (184 eyes; 7 patients were excluded) were included in this study. Seventeen patients were excluded as they were not able to complete both the Snellen chart and Peek Acuity examinations. One-year follow-up was undertaken in December 2019 at Sitanala Hospital, where 95 patients were seen. 
All procedures applied in this study which involved human participants were in accordance with the ethical standards and approved by the Medical Ethics Committee of Faculty of Medicine, Universitas Indonesia. The objective of the examination and study were explained to the participants, included risks and benefits for participants. Informed consent was described in Bahasa Indonesia to the participants or to the parent for child participants. Participants included in this study were those who gave written consent to participate, during or after completing multidrug leprosy therapy, and who underwent both measurements of Uncorrected Visual Acuity (UCVA) with Snellen Chart and Peek Acuity. Exclusion criteria included participants unable to complete the visual acuity measurement using the Snellen Chart and Peek Acuity , non-leprosy patients and those who did not consent to participate.

Participants received counseling about leprosy, disability prevention and rehabilitation after undergoing all of the examinations.

\section{DATA COLLECTION}

The visual acuity examination was conducted using the two different methods. First, the Snellen Chart examination was performed either by an ophthalmologist or an experienced optician. Afterward, Peek Acuity examination was performed by a general practitioner. Both tests were performed indoors under sufficient lighting. Patient characteristics such as gender, age, education level, occupation and duration of leprosy, were recorded.

In the first test, UCVA was tested using the standard Snellen Chart. The patient was asked to read from the biggest size of letters into the smallest size of letters that the patient could read on, each eye at a time from the distance of 6 meters. Visual acuity score is designated as the distance from the chart over the size of the smallest letter that can be read. If the patient was unable to read the biggest letter on the chart, we used the scale of counting fingers (CF), hand movement (HM), light perception (LP) and no light perception (NLP). We then classified the visual acuity score into one of four categories based on the World Health Organization (WHO) Vision Impairment Classification , namely, mild or no visual impairment (visual acuity is $\geq$ $6 / 18$ ), moderate visual impairment (visual acuity $<6 / 18$ to $\geq 6 / 60$ ), severe visual impairment (visual acuity is $<6 / 60$ to $\geq 3 / 60$ ) and blindness (visual acuity $<3 / 60$ to no light perception). ${ }^{12}$ The UCVA Snellen Chart measurement score was converted into logMAR score for statistical analysis.

In the second test, UCVA was tested using the Peek Acuity app (Android app, directly installed from the Google Play Store ). The application was installed to the smartphone and the screen brightness was set into maximal screen brightness within the application. The application uses only the letter ' $\mathrm{E}$ ' in 4 orientations. The patient points in the direction of the arms of ' $E$ ' perceived from a distance of 2 meters and the examiner records the answer by swiping across the screen in the same direction as mentioned by the patient. Each eye was tested separately. The test uses the touchscreen interface to record participants' responses without the examiner needing to see the screen. This method reduces non-verbal reaction (i.e.raised eye brow) from the examiner when the patient showed a wrong answer. For patients whose vision had the scale of counting fingers, hand movement, light perception, or no light perception, Peek Acuity offers a standardized alternative. For counting fingers, the application randomly presents between 1 and 4 bars and the correct or incorrect response is recorded on the screen. For hand movement, a solid black box, half-width of the screen, moves backward and forward across the screen. For light perception, the application switches on the phone's flashlight and the participant is asked to identify when they see the light come on and off, with the option to assess the perception of projection direction. Test completion is indicated 
by sound and vibration alert. Visual acuity measurement can be showed in logMAR or metric or imperial Snellen score based on user preference. The visual acuity scoring is done within the application and the examiner is blinded regarding the correct response. The UCVA Peek Acuity measurement score was converted into logMAR score for statistical analysis.

\section{DATA ANALYSIS}

All data were prospectively documented in the medical record and subsequently compiled in our electronic database. We converted the UCVA score from the Snellen Chart and Peek Acuity into $\log$ MAR score for statistical analysis. Scatter plots of the Snellen Chart and Peek Acuity logMAR measurements were made. The Bland-Altman method was used to reveal both systematic and random errors between the Snellen Chart and Peek Acuity. Bland-Altman is a scatter plot showing the differences between paired measurements. Mean differences close to zero show no systematic difference between the measured values of two tools. Calculating the Limit of Agreement (LoA) indicates how far apart the measurements are. If LoA is small, both methods can be used. If LoA is large, the new method is ineligible for substitution of the old method. ${ }^{13,14}$ Linear regression analysis was also performed.

Cohen's Kappa analysis was performed to show the degree of agreement between two tool measurement results with categorical variables. Cohen's Kappa score $K<0.20$ shows poor agreement, $0.21<K<0.40$ shows fair agreement, $0.41<K<0.60$ shows moderate agreement, $0.61<K<0.80$ shows good agreement, and $0.81<K<1.00$ shows very good agreement. Concordance rate analysis was performed to see the validity of new diagnostic measuring. A concordance rate of 70-79\% shows agreement, 80-89\% shows strong agreement, 90-98\% shows very strong agreement, and 99-100\% shows nearly complete agreement. We also used IBM SPSS Statistics 25 for statistical analysis.

\section{Results and discussion}

DEMOGRAPHIC DATA

Leprosy patients commonly have ocular complications, leading to more severe disability grading. Late diagnosis of visual impairment could lead to blindness and other ocular complications. Early screening of visual acuity using accessible tools could prevent blindness with early intervention and referral . Ophthalmic examination tools are often immobile and highly priced which makes them difficult to deploy in rural areas.

This population-based study involved 347 subjects (255 patients from Sitanala Hospital, Tangerang and 92 patients from Alverno Hospital, Singkawang) which included 692 eyes (2 eyes were anophthalmic) with male participants being in a 3:2 ratio to females $(62.2 \%$ male participants and $37.8 \%$ female participants). The youngest participant was 8 years old and the oldest participant was 95 years old, with mean age of the participants being $52.46 \mathrm{SD} \pm 13.36$ years old. Demographic indices are shown in Table 1.

This is the first study of leprosy patients in Indonesia intended to evaluate the reliability of Peek Acuity for visual acuity screening in a community setting . The participants in our study were predominantly men with 3:2 ratio, which is in line with the study of Mvogo et al. in Cameroon. ${ }^{15}$ In Asian countries, more men than women are registered with leprosy. Varkevisser et al. reported a case study in Aceh, Indonesia, revealed women were underreported due to strong traditions, low status of women, their limited mobility, illiteracy, and poor knowledge of leprosy. ${ }^{16}$ The mean age of the participants in this study was 52.46 years which is slightly lower than other studies on ocular complications of leprosy in Yemen (55.4 
Table 1. Demographic characteristics

\begin{tabular}{|c|c|c|}
\hline \multirow[b]{2}{*}{ Characteristics } & \multicolumn{2}{|c|}{ Number of subjects ( $n=347$ subjects) } \\
\hline & $n$ & $\%$ \\
\hline \multicolumn{3}{|l|}{ Gender } \\
\hline Male & 216 & 62.2 \\
\hline Female & 131 & 37.8 \\
\hline \multicolumn{3}{|l|}{ Occupation } \\
\hline Fixed income & 67 & 19.3 \\
\hline Non-fixed income & 116 & 33.4 \\
\hline Unemployed ${ }^{*}$ & 162 & 46.7 \\
\hline N/A** & 2 & 0.6 \\
\hline \multicolumn{3}{|l|}{ Education } \\
\hline Bachelor/Master & 3 & 0.9 \\
\hline Senior high school & 35 & 10.1 \\
\hline Junior high school & 29 & 8.4 \\
\hline Elementary school & 113 & 32.6 \\
\hline Uneducated & 167 & 48.1 \\
\hline \multicolumn{3}{|l|}{ Type of Leprosy } \\
\hline Paucibacillary & 97 & 28.0 \\
\hline Multibacillary & 228 & 65.7 \\
\hline N/A & 22 & 6.3 \\
\hline \multicolumn{3}{|l|}{ Duration of Leprosy } \\
\hline$\leq 5$ years & 150 & 43.2 \\
\hline $6-10$ years & 53 & 15.3 \\
\hline$>10$ years & 121 & 34.9 \\
\hline N/A** & 23 & 6.6 \\
\hline
\end{tabular}

* Participant is considered unemployed if he or she did not partake in an economically productive activity in the last 12 months preceding the study. ${ }^{* *}$ N/A: Not Available.

Table 2. Visual impairment based on WHO classification of visual impairment ${ }^{12}$

\begin{tabular}{lcc}
\hline & \multicolumn{2}{c}{ Number of subjects $(n=347$ subjects $)$} \\
\cline { 2 - 3 } Classification & $n$ & $\%$ \\
\hline Mild or no visual impairment & 222 & 64.0 \\
Moderate visual impairment & 92 & 26.5 \\
Severe visual impairment & 13 & 3.7 \\
Blindness & 21 & 5.8 \\
\hline
\end{tabular}

years) and Cameron (59.4 years). ${ }^{15,17}$ About half of the participants were unemployed (46.7\%) and uneducated $(48.1 \%)$. Another study in Sitanala Leprosy Village also revealed almost half of the subjects were unemployed $(47.4 \%)$ and had a low level of education.$^{18}$

\section{VISUAL IMPAIRMENT}

Uncorrected visual acuity (UCVA) score from the Snellen Chart test revealed that more than half of the participants had mild or no visual impairment $(64 \%)$, 26.5\% participants had moderate visual impairment, $3.7 \%$ participants had severe visual impairment, and 5.8\% participants had blindness. The results are shown in Table 2.

In this study, UCVA score with the Snellen Chart test revealed more than half of the participants had mild or no visual impairment (64\%). In another study, it showed that $14.3 \%$ of 


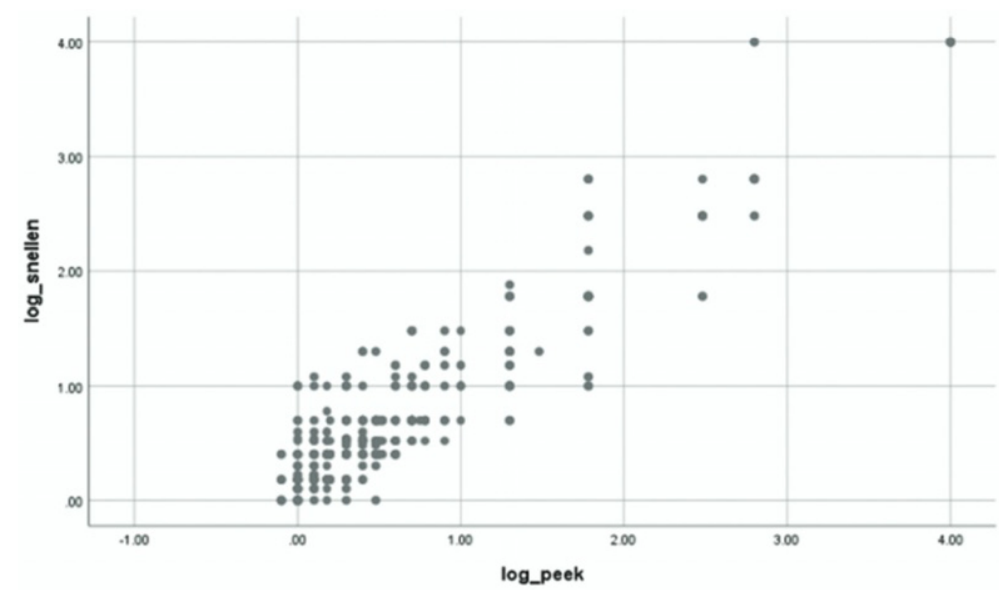

Figure 1 Scatterplot matrix of logMAR visual acuity scores using Snellen Chart and Peek Acuity $(n=347$ eyes).

leprosy patients were blind in one eye and $2 \%$ were blind bilaterally. ${ }^{19}$ Visual impairment can have a profound effect of quality of life and economic productivity. ${ }^{20}$ These patients are less likely to seek routine eye screening due to low level of knowledge and health awareness. Thus, an accessible and affordable eye screening tool is mandatory for this marginalized community.

\section{ANALYSIS}

The mean difference between the Snellen chart and Peek Acuity was $0.11 \log$ MAR (95\% CI, 0.096 to 0.13 ). Linear regression analysis showed no statistically significant difference between the Snellen Chart and Peek Acuity measurement $(P=0.98)$. There is no adverse event reported by participants during the examination. Cohen's Kappa of visual acuity measured with Peek Acuity application and the Snellen Chart was 0.65 . The concordance rate of visual acuity measured with Peek Acuity application and the Snellen Chart was 0.83. The X-axis from Figure 1 shows the logMAR score using Peek Acuity the Y-axis shows the logMAR score using the Snellen Chart. The Snellen Chart logMAR score varies between 0.00 to more than 3.00. The Peek Acuity logMAR score varies between -0.10 and more than 3.00 . The scatter of points suggests that most of the visual acuity examination using Peek Acuity and the Snellen Chart both provide consistent measurements. One-year follow up reveals that both the Snellen Chart and Peek Acuity have similar ranges of logMAR scores compared to the previous year (see Figure 2). The Snellen chart logMAR score varies between 0.00 and more than 3.00. The Peek Acuity $\operatorname{logMAR}$ score varies between -0.10 and more than 3.00. We can infer from the figure that most of the measurements using the Snellen Chart and Peek Acuity were still consistent despite the smaller samples ( $n=190$ eyes). In Figure 3, the X-axis shows the mean $\log$ MAR visual acuity scores between the Snellen Chart and Peek Acuity. The Y-axis shows the difference in $\log$ MAR visual acuity scores between the Snellen Chart and Peek Acuity. The Bland-Altman plot shows a bias near 0, indicating no systematic difference between the Snellen Chart and Peek Acuity visual acuity measurement. The limit of agreement (LoA) of the Snellen Chart and Peek Acuity was reported with 95\% CI. The Limit of Agreement was -0.38 to 0.61 . The Bland-Altman plot of one-year follow-up is presented in Figure 4. The LoA with total samples of 190 eyes at one-year follow-up was -0.32 to 0.46 , indicating that the two methods are essentially equivalent. 


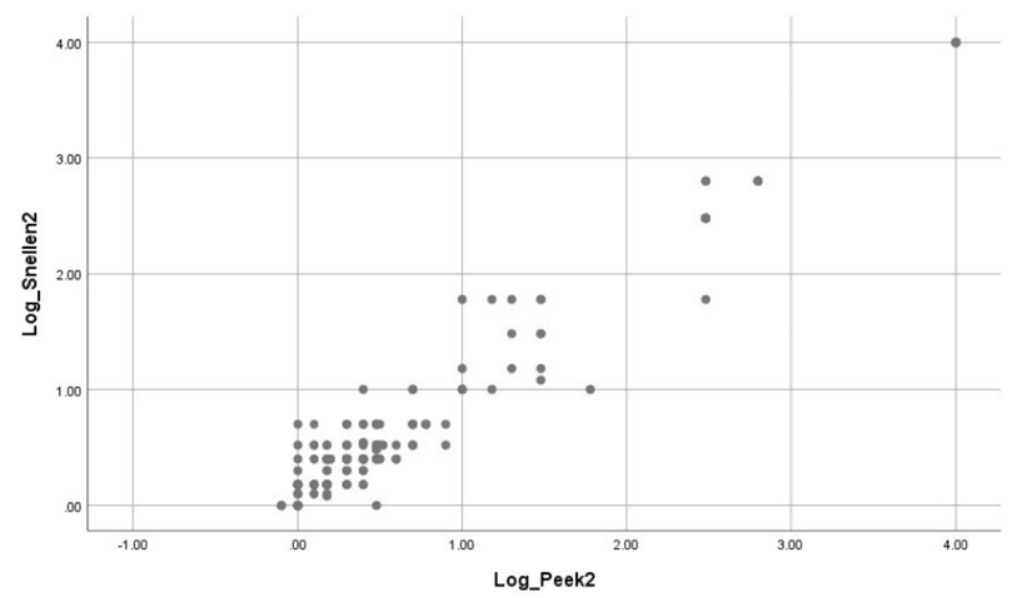

Figure 2 One-year follow-up in Sitanala's first cluster in 2019 of $\log$ MAR visual acuity scores using Snellen Chart versus Peek Acuity ( $n=190$ eyes).

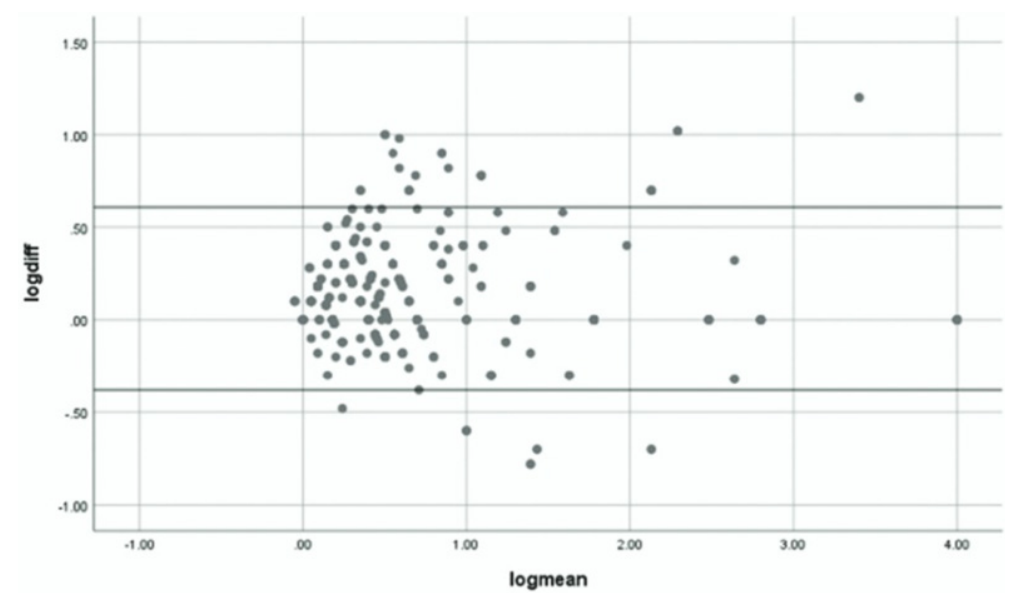

Figure 3 Bland-Altman plot of the differences in logMAR visual acuity scores using Snellen Chart and Peek Acuity Application $(n=347$ eyes $)$.

Nowadays, smartphone applications for healthcare are emerging constantly. Peek Acuity is a smartphone-based application for visual acuity screening that has been reported to have a consistent and repeatable measurement. ${ }^{5}$ Examination using a smartphone carries advantages in terms of practicality and ease. The high number of cell phones in use make Peek Acuity screening engaging. Without a better approach to visual acuity screening in the population, undiscovered and untreated vision abnormalities in leprosy patients can lead into permanent vision loss. One of the advantages using Peek Acuity application is the vibration alert that will notify the examiner when excessive light is detected. Hence, the examiner can readjust the room lighting. Another advantage is at the end of Peek Acuity examination, it will create a picture that simulate the visual blur as a representation of participants' vision to be shown to the family. Also, increased smartphone utilization can increase access for mobile health 


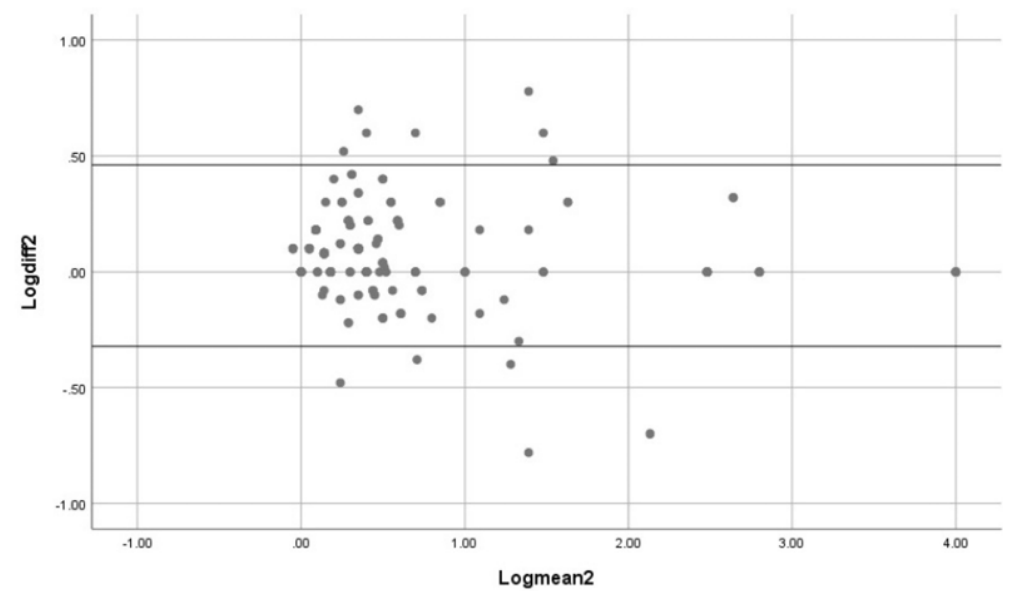

Figure 4 Bland-Altman plot of the differences in logMAR visual acuity scores using Snellen Chart and Peek Acuity Application in one-year follow-up $(n=190$ eyes $)$.

applications. Peek Acuity application is easy to apply and needs minimal training so it can be used in either a professional setting or a non-professional setting. This free-to-download application was created to provide cost-effective screening to the population with limited coverage by ophthalmic services. According to another study, Peek Acuity was acceptable to patients because of its effectiveness; it was perceived to be fast and able to reach a large number of people, and increase awareness of eye health in the population. The use of the ' $E$ ' letter in Peek Acuity can increase the objectivity of the test. Prior to this study, Peek Acuity has been evaluated as a visual acuity screening tool used for adult and child patients. ${ }^{8,21,22}$ The limitation of Peek Acuity is the smartphone that is more expensive than the paper-based Snellen Chart, but less expensive compared to retro-illuminated Snellen Chart or logMAR chart. However, with the increasing availability of low-cost smartphones, many health care professionals might already have one. ${ }^{5}$

Our study shows that the mean difference between the Snellen Chart and Peek Acuity was $0.11 \log$ MAR, indicating that Peek Acuity agreed well with the Snellen Chart. The result is in accordance with the study from Bastawrous et al. in Kenya who used the same method and revealed the mean difference between Peek Acuity and the Snellen chart as 0.08 logMAR (95\% CI, 0.06-0.10)..$^{5}$ Another study by Perera et al. showed the mean difference between the two methods was $0.02 \log$ MAR $(95 \%$ CI, $-0.33-0.37)$. Generally, there was no statistically significant difference between the mean $\log$ MAR acuity values of both charts. ${ }^{23}$

In linear regression analysis, the difference between the logMAR measurement using the Snellen Chart and Peek Acuity was not significantly different $(P=0.98)$. Even though it was not analyzed in this study, the time elapsed for examination using the Peek Acuity in practice was shorter and changes in ambient lighting were less of a problem in unexpected conditions such as electricity shortage. These issues should not be underestimated in community settings. According to another study, eye examination using Peek Acuity needs 2 to 20 minutes, compared to traditional eye examination which need 30-240 minutes. ${ }^{8}$ A study by Rono et $a l$. also reported benefits of visual acuity measurement by using Peek Acuity. ${ }^{20}$ It eases the examination in community-based screening, so patients who need further eye examination 
could be referred to ophthalmologists in the hospital. Therefore, it will increase the potential of Peek Acuity to improve eye health services.

In this study, Cohen's Kappa of visual acuity measured with Peek Acuity application and the Snellen Chart was 0.65 which means Peek Acuity has a good agreement compared to the Snellen Chart. Schlenker et al. also found similar kappa coefficient (0.67) in comparing traditional single optotype with computer-based visual acuity test for childhood amblyopia screening which is in the range of full agreement. ${ }^{24}$ The concordance rate of visual acuity measured with Peek Acuity application and the Snellen Chart was 0.83 which means Peek Acuity has a strong agreement with the Snellen Chart. A study by Toy et al. also found no difference existed between conventional visual acuity testing and smartphone measurement. ${ }^{25}$ From these results, Peek Acuity measurement could be suitable for assessing visual acuity compared to the Snellen Chart.

One limitation of this study was the language barrier between the patients and the examiners. There were some patients who spoke only the local language, so we needed the help of local health workers to translate to and from Bahasa Indonesia. Also, the small sample size at the one-year follow-up may have several explanations, including the inadequacy of patients' medical records at the leprosy hospital. Hence, coordination between every community health center and health cadres is necessary to report patients who are diagnosed and treated as leprosy patients in their area . Cooperation with the Ministry of Health is also required in order to monitor and evaluate the community engagement program. In spite of the small sample size, we could see from the one-year follow-up results (as in Figures 2 and 4) that Peek Acuity is helpful in detecting early visual acuity impairment in the screening of leprosy patients. We addressed the one-year follow-up in one cluster in Sitanala because of adjustments related to the financial support of the project. The second area is still to be visited for follow-up. Further studies and implementation of this community engagement program are still needed with obviously larger samples and better coordination of health workers in the leprosy endemic area for further evaluation and monitoring of leprosy patients. It is imperative that health workers in leprosy endemic areas are trained to use the Peek Acuity application, so they can do early screening and visual acuity evaluation periodically every 6 months for leprosy patients.

\section{Conclusion}

Peek Acuity, a smartphone-based application for visual acuity screening, is very applicable for use in low-middle income countries such as Indonesia due to its cost, accessibility and reliability. Our study demonstrates that Peek Acuity is an accurate and repeatable visual acuity screening tool as effective as the Snellen chart, which can be used for leprosy patients in order to overcome barriers in accessing eye health services, especially in rural areas.

Visual acuity examination using Peek Acuity can be done by anyone who has been trained, even non-medical personnel. If they find patients with a visual acuity of less than $6 / 18$, then they can be referred to an eye clinic or an ophthalmologist for further assessment.

\section{Conflict of Interest}

The authors report no conflict of interest.

\section{Funding}

This work is supported by the Community Engagement Grant of 2018 and 2019 by Directorate of Research and Community Engagement (Direktorat Riset dan Pengabdian Masyarakat) 
Universitas Indonesia, Sitanala Hospital Tangerang, Alverno Hospital Singkawang, Cendo Pharmaceutical Industries, Optik Tunggal Sempurna, Pancaraya Krisnamandiri, Carl Zeiss Pte. Ltd., Topcon Industries, Singkawang Eye Center for their medical equipment and drugs support. And also, this study is supported by Directorate Prevention and Control of Direct Transmitted Disease, Director General Disease Prevention and Control Health Ministry of Indonesia (Seksi Kusta dan Frambusia/Direktorat Penyakit Tropis Menular Langsung/Direktorat Pencegahan Dan Pengendalian Penyakit Menular Langsung (P2PML)/Ditjen Pencegahan Dan Pengendalian Penyakit (P2P) Kementrian Kesehatan Republik Indonesia).

\section{Contributorship}

Name of Guarantor: Yunia Irawati (Division of Plastic and Reconstructive Surgery, Department of Ophthalmology, Faculty of Medicine, Universitas Indonesia, Dr. Cipto Mangunkusumo Hospital, JEC Eye Hospitals and Clinics, Jakarta, Indonesia)

Phone number: +62816789595

Address: Jalan Kimia No. 8-10, Menteng, Central Jakarta, Indonesia, 10320

Email of Guarantor: e-mail: yunia_irawati@yahoo.com

\section{Patient Consent}

Informed consent was described in Bahasa Indonesia to the participants or to the parent for child participant. Participants included in this study were those who gave written consent to participate, during or had completed multidrug leprosy therapy, and underwent both measurements of Uncorrected Visual Acuity (UCVA) with Snellen Chart and Peek Acuity.

\section{Author Contribution}

A conceived the presented idea.

$\mathrm{C}$ and $\mathrm{E}$ developed the theory.

D performed the computation.

$F$ verified the analytical methods.

A encouraged $\mathrm{G}$ and $\mathrm{H}$ to investigate and supervised the findings of this work.

All authors discussed the results and contributed to the final manuscript.

\section{References}

1 Grzybowski A, Nita M, Virmond M. Ocular leprosy. Clin Dermatol, 2015; 33(1): 79-89.

2 Kumar B, Kar HK. IAL Textbook of Leprosy. 2nd edn, India: Jaypee Brothers Medical Publishers 2016.

3 Hogeweg M. Ocular leprosy. Int J Lepr, 2001; 69(2 (Suppl.)): S30-S35.

4 Hussain B, Saleh GM, Sivaprasad S, Hammond CJ. Changing from Snellen to LogMAR: debate or delay? Clin Exp Ophthalmol., 2006; 34(July 2005): 6-8.

5 Bastawrous A, Rono HK, Livingstone IA, Weiss HA, Jordan S, Kuper H et al. Development and validation of a smartphone-based visual acuity test (peek acuity) for clinical practice and Community-Based Fieldwork. JAMA Ophthalmol, 2015; 133(8): 930-937.

6 Rosser D, Laidlaw D, Murdoch I. The development of a 'reduced logMAR' visual acuity chart for use in routine clinical practice. Br J Ophthalmol, 2001; 85(4): 432-436.

7 Brady CJ, Egharari AO, Labrique AB. Smartphone-based visual acuity measurement for screening and clinical assessment. JAMA, 2015; 314(24): 2682-2683.

8 Lodhia V, Karanja S, Lees S, Bastawrous A. Acceptability, usability, and views on deployment of peek, a mobile phone mhealth intervention for eye care in Kenya: qualitative study. JMIR mHealth uHealth, 2016; 4(2): e30.

9 Organization WH. Global Leprosy Strategy 2016-2020. India; 2016.

10 Kemenkes RI. Data dan informasi profil Kesehatan Indonesia 2018. 2018. 
11 Irawati Y, Lestari YD, Bani AP, Menaldi SL, Wahyuni LK, Kurniawardhani DR. Health care service for leprosy patients in Sitanala Tangerang (A proposed approach of comprehensive health care for Leprosy patient). ASEAN J Community Engagem, 2018; 2(2): 281.

12 World Health Organization. Blindness And Vision Impairment Prevention. 2019.

13 Van Stralen KJ, Jager KJ, Zoccali C, Dekker FW. Agreement between methods. Kidney Int, 2008; 74(9): 11161120.

14 Kwiecien R, Kopp-Schneider A, Blettner M. Concordance analysis. Dtsch Arzteblatt Int, 2011; 108(30): 515521.

15 Mvogo CE, Bella-Hiag AL, Ellong A, Achu JH, Nkeng PF. Ocular complications of leprosy in Cameroon. Acta Ophthalmol Scand, 2001; 79(1): 31-33.

16 Varkevisser CM, Lever P, Alubo O, Burathoki K, Idawani C, Moreira TMA et al. Gender and leprosy: case studies in Indonesia, Nigeria, Nepal and Brazil. Lepr Rev, 2009; 80(81): 65-76.

17 Salem RAA. Ocular complications of leprosy in Yemen. Sultan Qaboos Univ Med J, 2012; 12(4): $458-464$.

18 Astutik E, Gayatri D. Perceived stigma in people affected by leprosy in leprosy village of Sitanala, Banten, Indonesia. Kesmas, 2018; 12(4): 178-186.

19 Malik ANJ, Morris RW, Ffytche TJ. The prevalence of ocular complications in leprosy patients seen in the United Kingdom over a period of 21 years. Eye [Internet], 2011; 25(6): 740-745, Available from: http://dx.doi .org/10.1038/eye.2011.43.

20 Rono HK, Bastawrous A, Macleod D, Wanjala E, DiTanna GL, Weiss HA et al. Smartphone-based screening for visual impairment in Kenyan school children: a cluster randomised controlled trial. Lancet Glob Heal, 2018; 6(8): e924-e932.

21 Zhao L, Stinnett SS, Prakalapakorn SG. Visual acuity assessment and vision screening using a novel smartphone application. J Pediatr, 2019; 213: 203-210.e1.

22 de Venecia B, Bradfield Y, Trane RM, Bareiro A, Scalamogna M. Validation of peek acuity application in pediatric screening programs in Paraguay. Int J Ophthalmol, 2018; 11(8): 1384-1389.

23 Morjaria P, Bastawrous A, Murthy GVS, Evans J, Gilbert C. Effectiveness of a novel mobile health education intervention (Peek) on spectacle wear among children in India: study protocol for a randomized controlled trial. Trials, 2017; 18(1): 1-10.

24 Schlenker MB, Christakis TJ, Braga-Mele RM. Comparing a traditional single optotype visual acuity test with a computer-based visual acuity test for childhood amblyopia vision screening: a pilot study. Can J Ophthalmol, 2010; 45(4): 368-374.

25 Toy BC, Myung DJ, He L, Pan CK, Chang RT, Polkinhorne A et al. Smartphone-based dilated fundus photography and near visual acuity testing as inexpensive screening tools to detect referral warranted diabetic eye disease. Retina, 2016; 36(35): 1000-1008. 